\title{
GERENCIAMENTO DO PROCESSO DE SECAGEM DE MADEIRAS
}

\section{WOOD DRYING PROCESS SUPERVISORY}

\author{
Elio José Santini ${ }^{1}$ Jorge Luís Monteiro de Matos ${ }^{2}$ Fábio Eduardo Scarabelot ${ }^{3}$
}

\begin{abstract}
RESUMO
Um sistema constituído de um microcomputador com software específico e um sistema de aquisição de dados, desenvolvido para gerenciar o processo de secagem de madeira em estufa, é descrito. Além de permitir a coleta de dados, o conjunto exerce controle sobre os sistemas de vaporização, ventilação e aquecimento, a partir dos valores obtidos pelos sensores. As temperaturas de bulbo seco e bulbo úmido, e o teor de umidade da madeira, foram responsáveis pelo controle e pelas mudanças das fases de secagem, respectivamente. $\mathrm{O}$ sistema demonstrou ser eficiente no controle do processo de secagem em estufa piloto. Contudo, sua aplicação em estufas comerciais depende de melhorias na proteção e ajustes dos sensores.
\end{abstract}

Palavras-chave: Secagem, controle da estufa, sistema computadorizado, sistema de aquisição de dados.

\begin{abstract}
A system made of a computer, a driving software and a data acquisition system, developed to drive the kiln-drying operation of wood, were described. More than sampling, the setting controls of the driving mechanisms of the kiln, such as vapor injection, venting, and heating, in conjunction with the reads of the wood moisture content and wet and dry bulb temperature. The system showed to be efficient to control the drying process of the pilot kiln. However, its application to commercial kilns depends upon improvements into sensors protection and calibration.
\end{abstract}

Key words: Kiln drying, kiln control, computerized system, data-acquisition system.

1. Engenheiro Florestal, Dr, Prof. Adjunto do Dep. de Ciências Florestais, Centro de Ciências Rurais, UFSM, 97105-900 - Santa Maria, RS.

2. Engenheiro Florestal, Dr., Prof. Adjunto do Dep. de Engenharia e Tecnologia Rurais, Setor de Ciências Agrárias, UFPR, 80035-010 - Curitiba, PR.

3. Engenheiro Eletricista, graduado pela UFPR, Engentronic, 80040-280 - Curitiba, PR. 


\section{INTRODUÇÃO}

Nos últimos 10 anos, pesquisas e desenvolvimentos sobre sistemas de aquisição de dados controlados por computador, com vistas ao monitoramento do processo de secagem da madeira, tem sido abordados com muita frequência na literatura mundial. $\mathrm{O}$ emprego de computadores para medir e controlar as variáveis mais importantes do processo de secagem, foram mencionados nos trabalhos de KORDES (1980a, 1980b) e BRUNNER (1981), coincidentemente, na época do surgimento do computador pessoal. O uso de sistemas automáticos (HOLMES (1988) e os progressos em automação das estufas no oeste do Canadá (MACKAY, 1988) também foram relatados. Uma revisão dos principais estudos realizados nos últimos anos sobre automação do processo de secagem de madeiras, foi apresentada por QUARLES \& WENGERT (1989).

A importância desses sistemas para o controle do processo de secagem em estufa é bastante abrangente. De acordo com KUUN \& VERMAAS (1989), durante a execução de um programa de pesquisa em secagem são coletados, registrados e analisados grande quantidade de dados, o que torna inevitável o uso de um sistema de controle e aquisição de dados computadorizado. Sistemas de aquisição de dados controlados por computador foram desenvolvidos por WELLING \& RESSEL (1985), NEVILLE \& VERMAAS (1988), LITTLE et al. (1986).

Nesses sistemas, são monitoradas as variáveis relacionadas às condições da câmara, qualidade da madeira e consumo de energia. Para KUUN \& VERMAAS (1988), a coleta de dados em tempo real, como temperaturas de bulbo seco e bulbo úmido, fluxo de ar e teor de umidade da madeira, induzem à finalização da secagem mais rapidamente e com menos defeito da madeira. Concluem, que uma das principais vantagens do sistema computadorizado, é a maior precisão ao manter os pontos de ajustes preestabelecidos.

NEVILLE \& VERMAAS (1988) desenvolveram uma estufa de laboratório, e adicionaram ao equipamento instrumentação auxiliar e técnicas de computação, de modo que todas as variáveis envolvidas no processo pudessem ser controladas através de um software. Pesquisadores da Universidade do Tennessee utilizaram um microcomputador para monitorar e controlar as operações de uma estufa experimental (LITTLE et al. 1986).

KUUN \& VERMAAS (1988) acreditam que o microcomputador pode ser uma ferramenta de manejo eficiente, quando usado como gerenciador num sistema de controle, geralmente conectado dentro de uma rede, junto com muitos outros controladores de processo inteligentes. Esses sistemas de controle podem ser empregados com muitas vantagens por serrarias que operam baterias de estufas de secagem. Todavia, o sucesso de qualquer método de controle de estufas de secagem depende da precisão de medição do teor de umidade da madeira (BRUNNER, 1981).

O presente trabalho aborda a descrição de um sistema computadorizado de controle e aquisição de dados desenvolvido na Universidade Federal do Paraná, bem como a instrumentação utilizada para gerenciar o processo de secagem de madeira serrada em uma estufa piloto. 


\section{INSTRUMENTAÇÃO DO SISTEMA DE GERENCIAMENTO}

O controle computadorizado da secagem de madeiras requer o emprego de dois equipamentos principais: uma estufa dotada de dispositivos que permitem regular as condições do ambiente interno, e um sistema de aquisição de dados para controlar seus acionamentos e coletar todas as informações relativas ao processo. Um diagrama simplificado do sistema de aquisição de dados desenvolvido e sua interação com uma estufa de secagem de madeiras, é mostrado na Figura 1.

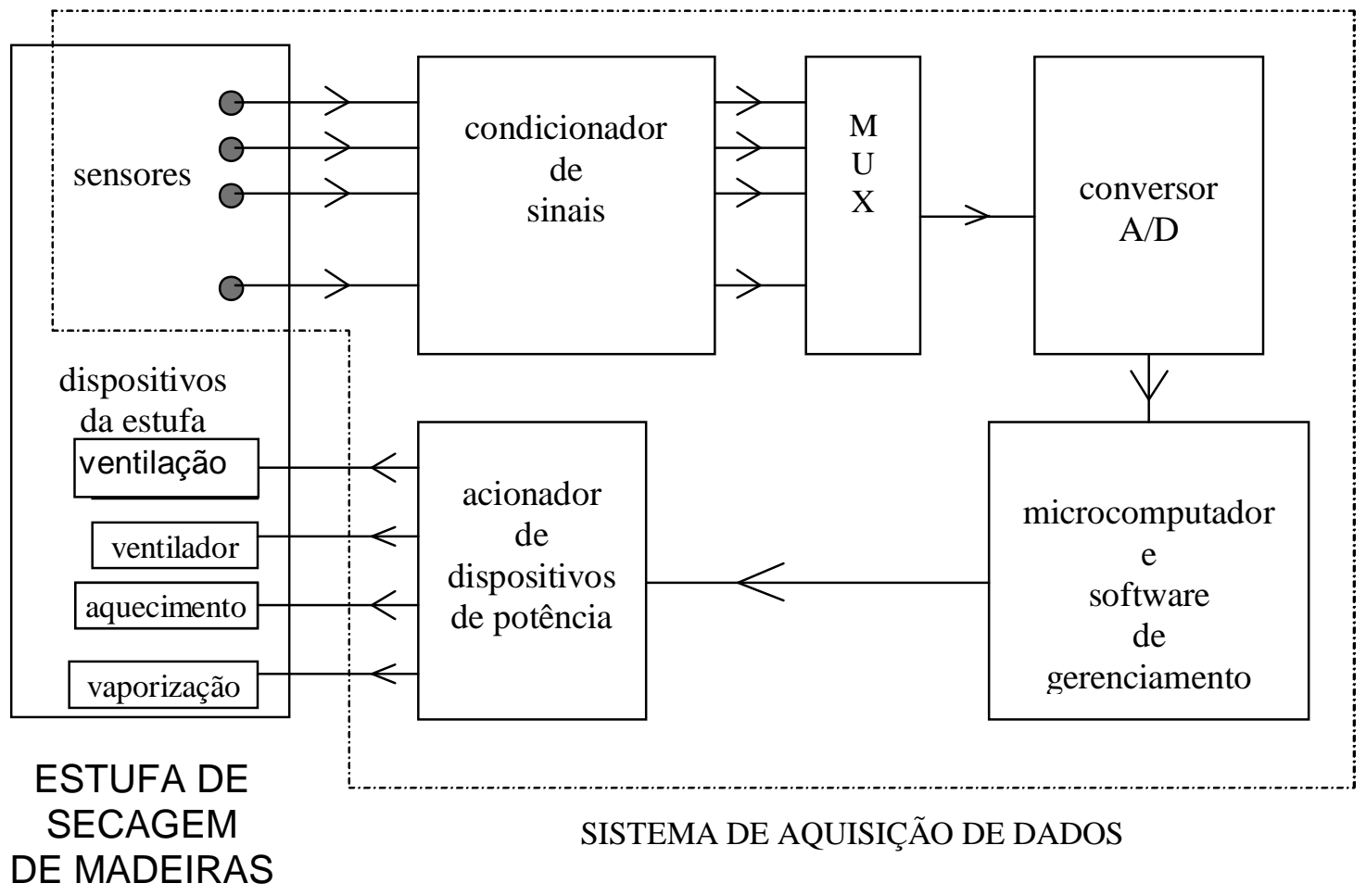

FIGURA 1: Diagrama simplificado do sistema de aquisição de dados e sua interação com uma estufa de secagem de madeiras.

\section{Componentes do sistema de aquisição de dados}

O sistema é constituído de 29 sensores eletrônicos, sendo que 20 foram destinados para leituras de temperatura, onde incluem-se as referentes ao ambiente, as da madeira, dos termômetros de bulbo seco e bulbo úmido; 8 para medições de resistência elétrica DC, e 1 para a leitura do peso da pilha de madeira, obtido a partir da célula de carga. Também fazem parte do sistema, o hardware (circuitos eletrônicos) e o software de gerenciamento, o qual utiliza um microcomputador para a sua operação. Todos os dados coletados foram registrados em arquivos no disco rígido, e permitem a 
entrada direta e compatível a outros softwares de processamento, tais como planilhas EXCEL® e SUPERCALC®, para análises posteriores.

\section{Sensores}

\section{Sensores de temperatura}

Constituído por um diodo comum, componente de baixo custo que oferece características adequadas de precisão e linearidade na faixa de operação proposta, situada entre 0 e $125^{\circ} \mathrm{C}$, com um erro máximo absoluto de $\pm 0,4^{\circ} \mathrm{C}$ e resolução de $0,05^{\circ} \mathrm{C}$. A partir da leitura dos termômetros de bulbo seco e bulbo úmido, são executados os acionamentos nos sistemas de aquecimento, vaporização e ventilação da estufa, de modo a manter as condições climáticas estabelecidas no programa de secagem.

\section{Sensores de resistência elétrica}

São pares de eletrodos metálicos que, cravados na face da largura da peça de madeira, permitem a obtenção da resistência elétrica. O condicionador de sinais aplica uma tensão de $-90 \mathrm{~V}$ entre os eletrodos e detecta a intensidade de corrente que circula pelos mesmos. Posteriormente, este valor é convertido em valor de resistência elétrica $(\Omega)$, através de equações intrínsecas ao software do sistema. Como a amplitude de leitura de resistência DC é bastante ampla, podendo variar, em função da espécie, temperatura, teor de umidade e outros fatores, desde alguns ohm até centenas de Giga-ohms (FORRER \& VERMAAS, 1987), a mesma foi dividida em duas faixas. A primeira, para baixa resistência, foi delimitada entre $30 \mathrm{k} \Omega$ e $10 \mathrm{M} \Omega$, e a segunda, para alta resistência, entre 10 $\mathrm{M} \Omega$ e $10 \mathrm{G} \Omega$. Foram usados eletrodos metálicos de $35 \mathrm{~mm}$ de comprimento e $4 \mathrm{~mm}$ de diâmetro, constituídos de liga de cobre, operando na faixa de $400 \mathrm{k} \Omega$ a $10 \mathrm{G} \Omega$, com um erro máximo absoluto de $\pm 6 \%$ e resolução em ponto flutuante de 0,05 .

\section{Sensor para medição de peso}

Uma célula de carga, considerada um transdutor do tipo "strain-gauge", foi utilizada para medição do peso da carga de madeira durante a secagem. A célula de carga em forma de "s", que pode ser usada tanto para tração como compressão, possui um recurso de taragem, opera na faixa de 0 a 450 kgf, com um erro máximo: $\pm 0,7$ kgf e resolução de 0,1 kgf.

\section{Condicionador de sinais}

Constitui-se de vários circuitos diferentes, que variam com o tipo de sensor. Tem como objetivo amplificar os baixos níveis de sinais dos sensores e ajustar suas variações para a faixa de entrada do conversor A/D (-2 volts a 2 volts). 


\section{Mux (multiplexador)}

Como o sistema não faz leituras simultâneas de todos os sensores, e sim de forma seqüencial, é necessário um componente para selecionar o sensor cuja grandeza relacionada deva ser medida. Esta tarefa é realizada pelo multiplexador, que após receber do microcomputador o respectivo endereço faz, na seqüência, a conexão elétrica deste sensor até a sua saída.

\section{Conversor $A / D$}

Tem como função a conversão dos sinais analógicos oriundos do multiplexador, em sinais digitais. Estes sinais, referentes ao valor de medição de determinado sensor, são enviados ao computador para posterior processamento. A conversão A/D é realizada por um circuito integrado, com resolução de 12 bits, através do método de rampa dupla.

\section{Microcomputador e software residente}

O microcomputador utilizado foi um 386 DX, 40 MHz e 4 MB de memória RAM, com disco rígido de $240 \mathrm{MB}$ IDE e monitor colorido SVGA. A unidade central de processamento possui dois drives para disco flexível, sendo um para 51/4" (1,2 MB) e outro para 31/2" (1,44 MB) e uma impressora Epson LQ-570 acoplada.

Para gerenciar o sistema, utilizou-se um software elaborado especificamente para este fim, residente no microcomputador, cujo fluxograma é apresentado na Figura 2. Constitui-se no elemento principal do sistema, e suas funções mais importantes são: a leitura (medição) de todos os sensores, o processamento e registro dos dados (os preestabelecidos e os coletados durante a secagem), e acionamentos, que ativam todos os dispositivos que mantém as condições climáticas da estufa.

\section{Acionador de dispositivos de potência}

É a parte do sistema constituído de componentes eletroeletrônicos, que recebe os sinais de comandos de baixa potência, oriundos do microcomputador, para acionar os dispositivos de alta potência que geram as condições de secagem.

\section{Dispositivos da estufa de secagem}

Os componentes responsáveis pela conservação das condições internas da estufa, como o sistema de vaporização (injeção de vapor), o sistema de ventilação (entrada e saída de ar) e o sistema de aquecimento (trocadores de calor), foram acionados e controlados pelo sistema de aquisição de dados. Esses acionamentos foram executados a partir das leituras dos sensores de temperatura de bulbo seco e bulbo úmido, e da célula de carga, com base nos valores preestabelecidos no programa de secagem. Uma descrição sucinta dos elementos de acionamento, é apresentada a seguir: 

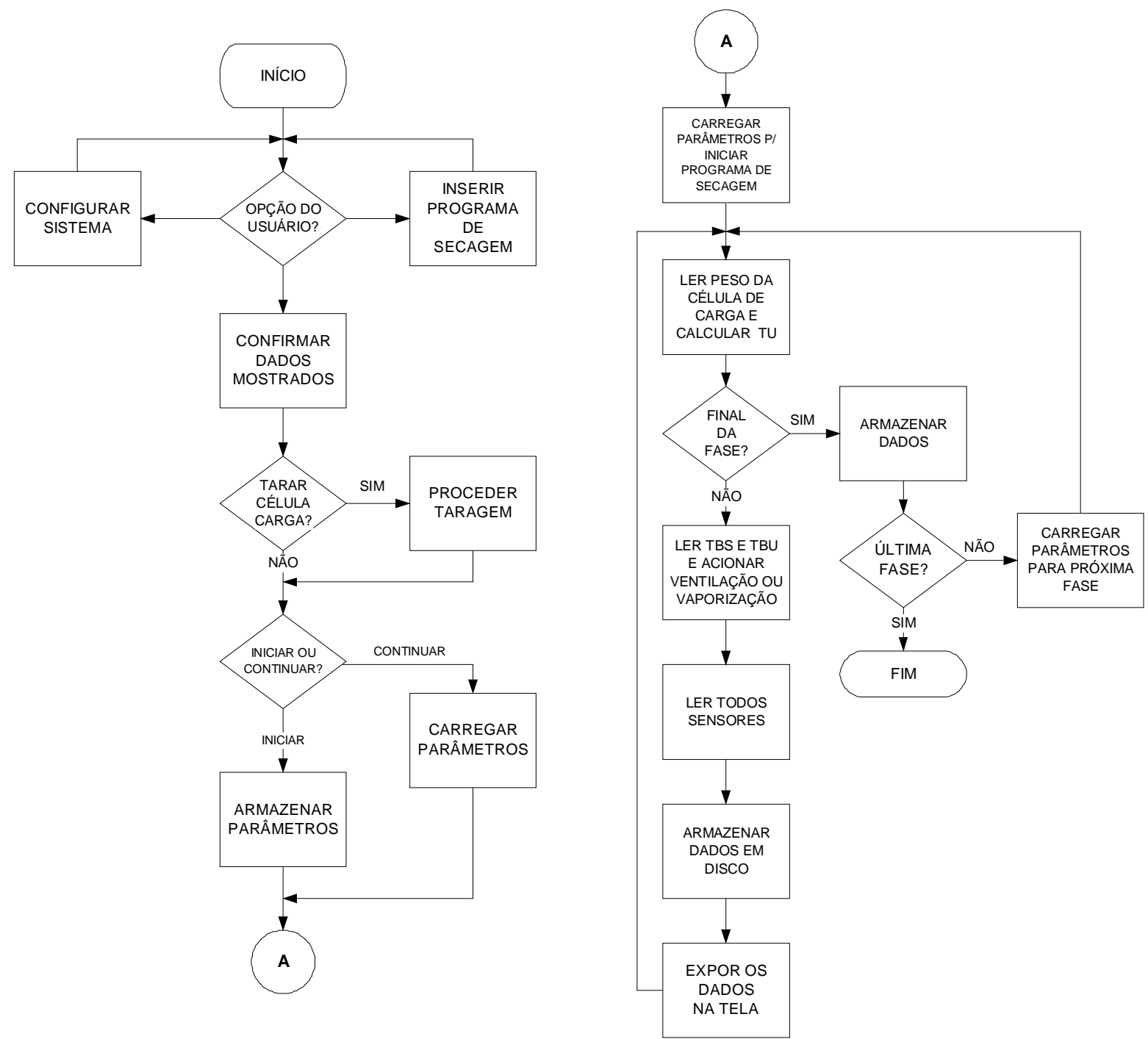

FIGURA 2: Fluxograma do software de controle do processo de secagem.

\section{Sistema de aquecimento}

Trocadores de calor da estufa, que são compostos de três resistências blindadas, ligadas em triângulo, totalizando $9 \mathrm{kVA}$ de potência (46000 BTU/h). O acionamento deste elemento é realizado através de um relé eletromagnético (contactor).

\section{Sistema de vaporização}

A produção de vapor da estufa é feita por uma caldeira, composta de um recipiente metálico que contém água e resistências elétricas, as quais são acionadas por um contactor quando o ambiente de secagem requer a injeção de vapor. 


\section{Sistema de ventilação}

A ventilação da estufa é realizada através de duas janelas, dotadas de relé para abertura e fechamento, sendo uma para entrada de ar externo e outra para saída de ar do interior da estufa (saturado de umidade).

\section{Sistema de circulação de ar}

Um motor elétrico trifásico de $2 \mathrm{HP}$ movimenta um ventilador, que propicia a circulação do ar através da pilha de madeira. O motor é acionado através de um contactor, cujo controle é realizado pelo módulo de acionamentos.

O sistema foi dotado, ainda, de recursos de proteção contra eventuais falhas, principalmente nos sensores de temperatura do bulbo seco e bulbo úmido, e na célula de carga, para aumentar a segurança do sistema.

\section{APLICAÇÃO DO SISTEMA NA SECAGEM DE MADEIRAS}

\section{Razões para o uso do sistema}

O emprego cada vez mais frequente de sistemas computadorizados para controle do processo de secagem de madeiras deve-se às exigências em qualidade e à elevação dos custos da madeira e de energia. O controle preciso das condições da estufa, a supervisão do processo em tempo real e a possibilidade de interferir a qualquer momento no programa de secagem, permitem economia de energia, devido a finalização mais rápida do processo, e melhoria na qualidade do produto final.

\section{Funcionamento do sistema de gerenciamento}

$\mathrm{O}$ equipamento permite medir e controlar as temperaturas de bulbo seco e de bulbo úmido através de acionamentos do trocador de calor, das aberturas de entrada e saída de ar e do sistema de produção de vapor, os quais conservam as condições da estufa estabelecidas pelo programa de secagem. O teor de umidade da madeira pode ser monitorado, ou pelo método de pesagem da pilha, que utiliza uma célula de carga tipo tração, ou através de medidores elétricos que usam modelos matemáticos resultantes da relação resistência elétrica/umidade.

As fases do programa de secagem, definidas para cada condição de temperatura de bulbo seco e bulbo úmido, são alteradas gradativamente pelo software de controle, em função do teor de umidade da madeira.

As informações referentes ao programa de secagem e teor de umidade inicial da madeira são introduzidas no sistema antes do início do processo. Após sua inicialização, o sistema carrega uma fase do programa, lê os valores dos sensores de bulbo seco e bulbo úmido e faz os acionamentos necessários para manter as condições ambientais da estufa dentro dos limites estabelecidos pelo mesmo. Em seguida, faz as medição dos demais sensores, processa e armazena os dados em mídia- 
magnética, e verifica se a fase do programa foi concluída. Caso positivo, o sistema carrega a fase seguinte, repetindo novamente toda a rotina, até que a última fase do programa seja executada.

Parâmetros adicionais como temperatura da madeira, queda da temperatura através da pilha (TDAL) e gradientes de temperatura e umidade também podem ser monitorados para fins de controle. Alguns sistemas podem ainda fazer alterações na velocidade do ar (KARAVAEVA et al., 1987), desde que o motor do ventilador seja equipado de mecanismo de velocidade ajustável.

As principais variáveis monitoradas no estudo de SANTINI (1996), o qual foi conduzido numa estufa piloto com capacidade para $1,0 \mathrm{~m}^{3}$ de madeira serrada, estão assinaladas na Figura 3. Além dessas, a TDAL, a temperatura da madeira, a resistência elétrica e o peso da carga de madeira, também foram medidas.

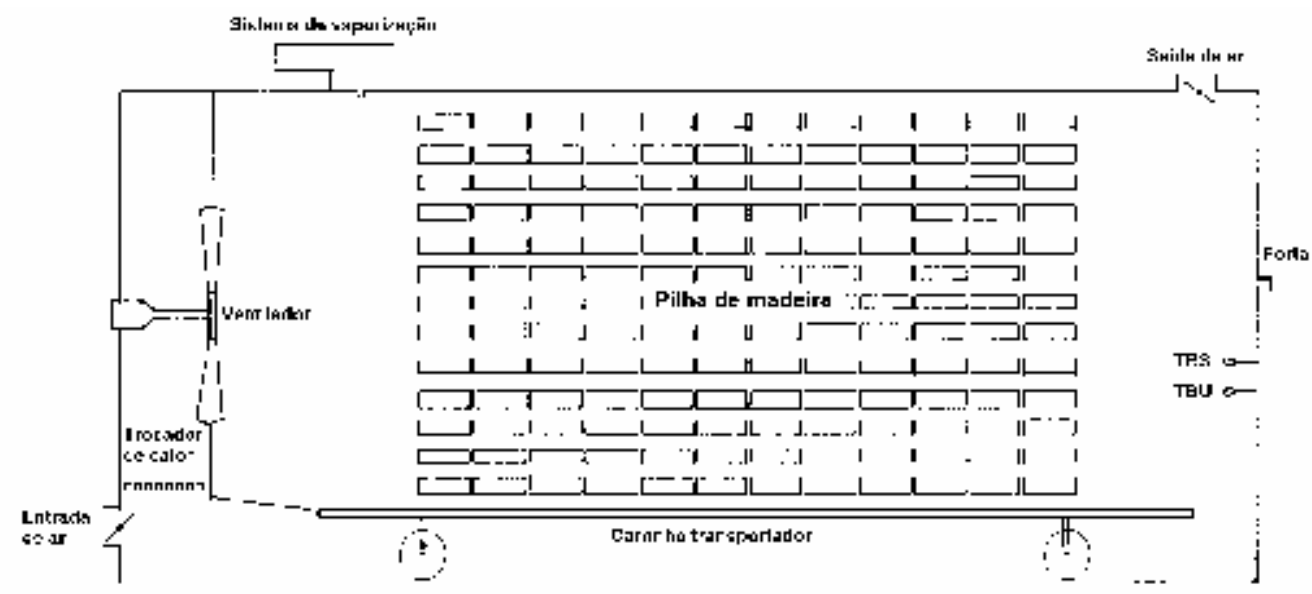

FIGURA 3: Estufa piloto e localização de alguns senores monitorados.

\section{Curva de secagem e controle do processo}

As curvas de teor de umidade, temperaturas de bulbo seco e bulbo úmido, resultantes da secagem da madeira de Pinus elliottii a alta temperatura, são mostradas na Figura 4. Para confeccioná-las, foram usadas todas as leituras efetuadas durante o procedimento de secagem, gravadas a cada 80 segundos, aproximadamente.

A dispersão evidenciada nas observações, particularmente nas leituras da temperatura de bulbo seco, deve-se, principalmente, à baixa velocidade de ar $(2,3 \mathrm{~m} / \mathrm{s})$ utilizada nesta operação de secagem. 


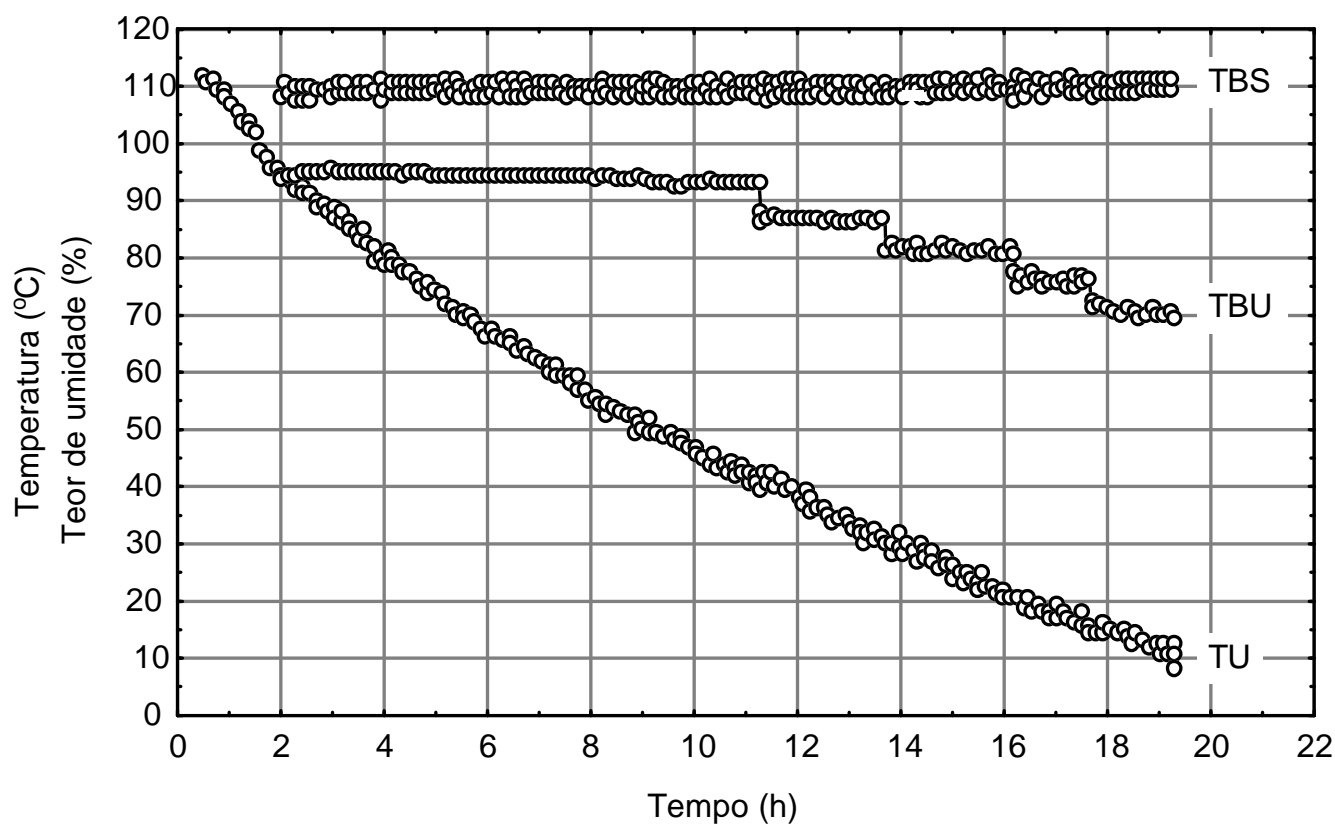

FIGURA 4: Curvas de teor de umidade (TU), temperatura de bulbo seco (TBS) e de bulbo úmido (TBU) obtidas durante a secagem da madeira de Pinus elliottii a alta temperatura.

As curvas resultantes da secagem à temperatura de $110^{\circ} \mathrm{C}$ e velocidade de ar de $2,3 \mathrm{~m} / \mathrm{s}$, apresentadas na Figura 4, evidenciam que o controle realizado pelo sistema a partir de um programa de secagem previamente elaborado, foi bem sucedido. A curva de secagem confeccionada a partir das leituras de uma célula de carga, mostrou um comportamento típico para o tipo de material e processo de secagem utilizados. A finalização do processo de secagem ocorreu quando a madeira atingiu $10 \%$ de umidade, e foi executada em tempo real pelo acionamento da célula de carga, através de um software de controle.

\section{AVALIAÇÃO TÉCNICA E OPERACIONAL DO SISTEMA}

O sistema de gerenciamento desenvolvido para controlar o processo de secagem de madeira serrada em estufa, apresenta as seguintes características principais:

a) Sua grande capacidade de armazenamento de dados possibilita um controle completo e rigoroso de todas as variáveis envolvidas no processo de secagem;

b) Permite leituras em tempo real das variáveis monitoradas, o que agiliza a tomada de decisão e pronta interferência no processo de secagem;

c) Possibilita a geração rápida de relatórios em qualquer fase da secagem, o que facilita o planejamento da produção; 
d) O sistema de controle do processo de secagem se baseia no teor de umidade da madeira, o que requer uma determinação eficiente do mesmo. $\mathrm{O}$ método de pesagem da carga através de célula de carga foi o mais apropriado, devido a baixa dispersão observada;

e) A proteção dos sensores de temperatura apresentou falhas, principalmente em razão do tipo de material empregado e do tempo de exposição às condições de secagem. Melhoria no sistema protetivo e ajustes mais acurados dos sensores de medição, são recomendados.

A avaliação técnico-operacional do sistema de gerenciamento desenvolvido para a estufa piloto, indica que o mesmo apresenta perspectivas promissoras de aplicação na indústria madeireira. Entretanto, em razão dos aperfeiçoamentos técnicos necessários, sugere-se a realização de testes em estufas comerciais, visando avaliar o desempenho da instrumentação de controle do processo de secagem em escala industrial.

\section{REFERÊNCIAS BIBLIOGRÁFICAS}

BRUNNER, R. Current control techniques for timber drying. 3. Computerized control. Holz RohWerkstoff, Berlin, v. 39, n. 1, p. 11-15, Jan. 1981.

HOLMES, S. A shopper's guide to electronic kiln controls. For. Ind., San Francisco, v. 115, n. 7. p. T10-T14, July 1988.

KARAVAEVA, N.M. et al. Automated technological process control system for kiln seasoning of lumber. Derev. Prom., Moscow, n. 12, p. 12-14, 1987. For. Prod. Abstr., Farnham Royal, v. 12, n. 7, p. 150, 1989. Ref. 1241. Resumo.

KORDES, W. Current control techniques for timber drying. 1. Drying techniques and measurement of control data. Holz Roh-Werkstoff, Berlin, v. 38, n. 11, p. 419-422, Nov. 1980a.

KORDES, W. Current control techniques for timber drying. 2. Conventional control devices. Holz Roh-Werkstoff, Berlin, v. 38, n. 12, p. 445-48, Dec. 1980b.

KUUN, C.P.; VERMAAS, H.F. The supervisory PC in process control system with special reference to the kiln drying of wood. Holz Roh-Werkstoff, Berlin, v. 46, n. 1, p. 27-31, Jan. 1988.

KUUN, C.P.; VERMAAS, H.F. Computerized data-acquisition and control system for an experimental pressure steam dryer for lumber. Holz Roh-Werkstoff, Berlin, v. 47, n. 7, p. 261265, July 1989.

LITTLE, R.L.; MOSCHLER, W.W.; TOENNISSON, R.L. Design of a computer based controllerrecorder for an experimental dry kiln. For. Prod. J., Madison, v. 36, n. 11/12, p. 72-74, Nov./Dec. 1986.

MACKAY, J.F.G. Kiln drying advances in western Canada. For. Ind., San Francisco, v. 115, n. 7 , p. T22-T24, July 1988.

NEVILLE, C.J.; VERMAAS, H.F. Laboratory kiln for the development of low temperature wood drying schedules. Holz Roh-Werkstoff, Berlin, v. 46, n. 7, p. 269-273, July 1988. 
QUARLES, S.L.; WENGERT, E.M. Applied drying technology, 1978 to 1988. For. Prod. J., Madison, v. 39, n. 6, p. 25-38, June. 1989.

SANTINI, E.J. Alternativas para monitoramento e controle do processo de secagem de madeira serrada em estufa. Curitiba, 1996. 198p. Tese (Doutorado em Ciências Florestais) Setor de Ciências Agrárias, Universidade Federal do Paraná.

VERMAAS, H.F.; NEVILLE, C.J. Low temperature drying of Eucalyptus grandis. A preliminary laboratory evaluation. Holzforschung, Berlin, v. 42, n. 4, p. 265-271, Aug. 1988.

WELLING, J.; RESSEL, J.Computergesteuertes datenerfassungssystem für die schnittholztrocknung. Holz Roh-Werkstoff, Berlin, v. 43, n. 4, p. 131-134, Apr. 1985. 